\title{
Hydrogen Production From Steam Gasification of Palm Kernel Shell Using Sequential Impregnation Bimetallic Catalysts
}

\author{
Anita Ramli \\ Department of Fundamental and Applied Sciences, \\ Universiti Teknologi PETRONAS, \\ 31750 Tronoh, Perak, Malaysia \\ anita_ramli@petronas.com.my
}

\author{
Siti Eda Eliana Misi, Mas Fatiha Mohamad, Suzana \\ Yusup \\ Department of Chemical Engineering, \\ Universiti Teknologi PETRONAS \\ 31750 Tronoh, Perak, Malaysia
}

\begin{abstract}
Zeolite $\beta$ supported bimetallic Fe and Ni catalysts have been prepared using sequential impregnation method and calcined at temperatures between $500-700{ }^{\circ} \mathrm{C}$. The catalytic activity of these catalysts in a steam gasification of palm kernel shell was tested in a fixed-bed quartz micro-reactor at $700{ }^{\circ} \mathrm{C}$. Both $\mathrm{Fe}$ and $\mathrm{Ni}$ active metals present in FeNi/BEA and NiFe/BEA catalysts are corresponding to $\mathrm{Fe}_{2} \mathrm{O}_{3}$ and $\mathrm{NiO}$. Different calcination temperatures and different sequence in metal addition have a significant effect to the catalytic activity where FeNi/BEA (700) shows the highest hydrogen produced than other catalysts.
\end{abstract}

Keywords-bimetallic catalyst; sequential impregnation method; hydrogen production; palm kernel shell

\section{INTRODUCTION}

The development on biomass gasification system is an important strategy for future green technology to protect the environment from $\mathrm{CO}_{2}$ emission. The conversion of biomass to hydrogen is the promising route since it can be used as an alternative fuel for transportation and power generation. On the other hand, if the process produces syngas, it may be utilized to produces methanol and Fisher-Tropsch oil. [1-2]. Generally, the gasification of biomass at high temperatures yield a product gas composed of $\mathrm{CO}, \mathrm{CO}_{2}, \mathrm{H}_{2} \mathrm{O}, \mathrm{H}_{2}, \mathrm{CH}_{4}$, higher hydrocarbons, tars, char, and ash [2-3]. The formation of tar and char are undesirable because the components could limit the hydrogen production and reduce the efficiency of the gasification process [4]. The nature of the tar produced is principally affected by the type of biomass, gasification process, gasifying agent and the operating conditions [3].

The application of metal based catalysts such as nickel (Ni), Cobalt (Co), Iron (Fe), Ruthenium (Ru) and Platinum (Pt) in biomass gasification is an effective method in reducing tar content. Among these catalysts, supported Rhodium (Rh) catalyst showed the best performance in steam gasification whereby catalyst having Rh loading of $1.2 \times 10^{-4} \mathrm{Rh}$ atom for each $g$ of catalyst can convert $98-99 \%$ of the carbon in biomass to products at $873 \mathrm{~K}$ [5]. However, Ni and Fe based catalysts are the preferred choice due to their wide availability and cheapness [4, 6-7]. Moreover, Ni and Fe based catalyst allows both methane reforming and water gas shift activity during the gasification process thus provide adjustment of the $\mathrm{H}_{2} / \mathrm{CO}$ ratio in the product gas [8-9].

Nevertheless, the activity of the $\mathrm{Ni}$ based catalyst is influence by $\mathrm{Ni}$ loading and $\mathrm{Ni}$ dispersions [4]. This is due to migration of metallic particles to form larger aggregates thus, reducing the dispersion of catalyst and consequently reducing the catalyst activity [10]. Some studies have demonstrated that the nickel sintering could be limited when nickel oxide has strong interaction with promoter [9] or support [11] and have well defined structure like perovskite [10]. Dolomite and olivine which contains Fe helps stabilize $\mathrm{Ni}$ in the support and gives an important effect on precursor reducibility as well as catalytic properties [6]. Chaiprasert and Vitidsant [9] also verified that the addition of metallic noble metals as promoter may help to improve the metallic dispersion, decrease sintering and enhance the thermal stability.

In this study, zeolite $\beta$ (BEA) supported $\mathrm{Fe}$ and $\mathrm{Ni}$ catalysts with different sequence in addition of the second metal have been proposed for steam gasification of palm kernel shell (PKS) for hydrogen production. The effects of second metal and calcination temperatures of the catalysts on the composition of gaseous product were investigated.

\section{MethODOLOGY}

\section{A. Biomass Preparation}

The biomass considered in this study is PKS, collected from palm plantation industry at Felda Nasaruddin, Perak. The PKS was dried at $110{ }^{\circ} \mathrm{C}$ before they were crushed and sieved to $500 \mu \mathrm{m}$.

\section{B. Catalyst Preparation}

The bimetallic catalysts were prepared via a sequential impregnation method. First, BEA was calcined at $500{ }^{\circ} \mathrm{C}$ for 16 hrs. First, 5\% Ni/BEA and 5\% Fe/BEA catalysts were prepared [Anita et al. 2013]. The second metal was introduced in the second impregnation step using another $5 \mathrm{wt} \%$ of $\mathrm{Fe}$ and $\mathrm{Ni}$ metal, yielding $5 \% \mathrm{Fe} 5 \% \mathrm{Ni} / \mathrm{BEA}$ and $5 \% \mathrm{Ni} 5 \% \mathrm{Fe} / \mathrm{BEA}$ which are designated as FeNi/BEA (T) and NiFe/BEA (T). In 
general the catalysts are YX/BEA (T) where metal $\mathrm{X}$ was impregnated first followed by metal $\mathrm{Y}$ and $\mathrm{T}$ is the calcination temperature in ${ }^{\circ} \mathrm{C}$.

\section{Catalyst Characterization}

$\mathrm{N}_{2}$ adsorption-desorption isotherm (Quantachrome ASAP 2000) was used to determine the surface properties of the bimetallic catalysts. Powder X-ray Diffraction (XRD) patterns were obtained with a Bruker D8 Advance diffractometer using $\mathrm{Cu}-\mathrm{K} \alpha$ radiation to identify the crystalline phases of FeNi/BEA and NiFe/BEA catalysts. Temperature Programmed Reduction (TPR) experiments were performed on Thermo Finnigan TPDRO 1100 to determine the reducibility of the metal present on the catalyst surface and to investigate the interaction between the metals and support.

\section{Catalyst Testing}

Experiments were performed in a fixed bed quartz micro reactor (15 $\mathrm{mm}$ i.d.) in an electric furnace. The mixture of PKS and catalyst bed was held in place by quartz wool in the tubular reactor. The steam gasification reaction was performed at $700{ }^{\circ} \mathrm{C}$ temperature with catalyst/PKS ratio of $1: 3$, steam/PKS ratio of 4:1 and steam/Argon ratio of 1:6 (vol.). Two thermocouples were used to measure the temperature; one is placed at the centre of the bed in the tubular reactor and the other is placed on the outer surface of the reactor. Helium and Nitrogen were used as diluents gases and its flow was regulated by mass flow meter. Mass flow meter adjusted the gas flow in the range of $20-30 \mathrm{ml} \mathrm{min}{ }^{-1}$. Water is introduced by liquid pump, where they were quickly evaporated at elevated temperature and then carried to the tubular reactor by inert flow.

The outlet gas was passed through iced water condenser to substantially condense the water before it entered the gas chromatograph (GC). The gaseous product were analysed using an online gas chromatograph (VARIAN CP-3800) equipped with thermal conductivity detector (TCD) and fitted with TDX-01 column with Argon as a carrier gas. This analysis only focuses on the main product which is $\mathrm{H}_{2}, \mathrm{CH}_{4}$, $\mathrm{CO}_{2}$ and $\mathrm{CO}$ gases.

\section{RESULTS AND DISCUSSION}

\section{A. Catalyst Characterization}

The physicochemical properties of the FeNi/BEA catalysts have been reported in our previous works [13]. Therefore, this section will only be discussed in general in order to understand better the comparison between FeNi/BEA and $\mathrm{NiFe} / \mathrm{BEA}$ as well as the effect in the biomass steam gasification. Based on $\mathrm{N}_{2}$ adsorption-desorption, the textural properties like BET surface area, pore volume and pore diameters of the catalysts prepared are summarized in Table 1 where all the bimetallic catalysts have lower surface area and smaller pore volume as compared to the bare BEA. An increase in calcinations temperature does not have a significant effect on the surface area of the bimetallic catalysts. However, the average pore diameter of the bimetallic catalysts is bigger than that of bare BEA.
Table 1. Surface properties of the catalysts

\begin{tabular}{|c|c|c|c|}
\hline Catalysts & $\begin{array}{c}\text { BET } \\
\text { Surface } \\
\text { Area }\left(\mathbf{m}^{2}\right. \\
\left.\mathbf{g}^{-1}\right) \\
\end{array}$ & $\begin{array}{c}\text { Pore } \\
\text { Volume } \\
\left(\mathrm{cm}^{3} \mathrm{~g}^{-1}\right)\end{array}$ & $\begin{array}{c}\text { Average } \\
\text { Pore } \\
\text { Diameter } \\
\text { (nm) } \\
\end{array}$ \\
\hline BEA (500) & 529 & 0.15 & 4.30 \\
\hline FeNi/BEA (500) & 445 & 0.12 & 5.71 \\
\hline $\mathrm{NiFe} / \mathrm{BEA}(500)$ & 447 & 0.13 & 5.88 \\
\hline FeNi/BEA (600) & 441 & 0.12 & 5.83 \\
\hline $\mathrm{NiFe} / \mathrm{BEA}(600)$ & 454 & 0.13 & 5.61 \\
\hline FeNi/BEA (700) & 449 & 0.09 & 5.34 \\
\hline $\mathrm{NiFe} / \mathrm{BEA}(700)$ & 434 & 0.09 & 6.23 \\
\hline
\end{tabular}

Fig. 1 shows the diffraction patterns displayed by FeNi/BEA and NiFe/BEA catalysts. The presence of both $\mathrm{Ni}$ and $\mathrm{Fe}$ were detected in the prepared catalysts with the diffraction peaks corresponding to $\mathrm{NiO}$ phase and $\alpha-\mathrm{Fe}_{2} \mathrm{O}_{3}$ phase, respectively. The peaks for $\mathrm{NiO}$ phase are represented by the appearance of $\mathrm{Ni}(111)$ and $\mathrm{Ni}(200)$ planes at the $2 \theta=37.3^{\circ}$ and $43.3^{\circ}$ while the diffraction peaks corresponding to $\alpha-\mathrm{Fe}_{2} \mathrm{O}_{3}$ phase are represented with the appearance of $\mathrm{Fe}(104)$ and $\mathrm{Fe}(110)$ planes positioned at the $2 \theta=33.1^{\circ}$ and $35.6^{\circ}$. These planes are in agreement with data reported in the JCPDS card and those reported in previous studies [14-15].

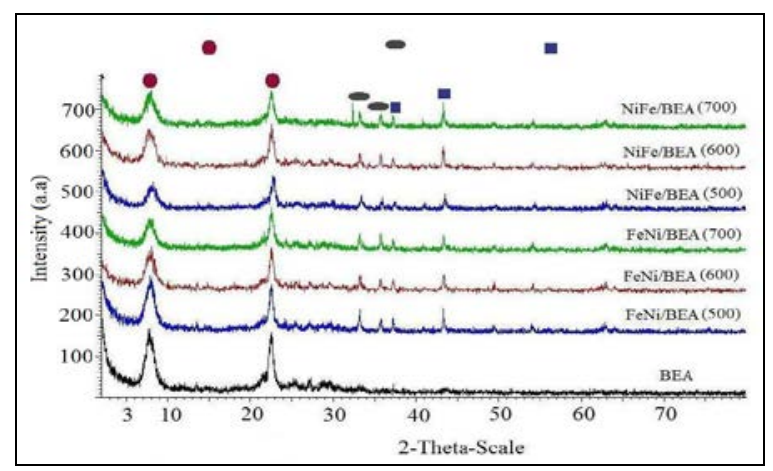

Fig. 1. The diffraction patterns of the bimetallic catalysts

Furthermore, presence of $\mathrm{NiO}$ and $\alpha-\mathrm{Fe}_{2} \mathrm{O}_{3}$ phase in the bimetallic catalysts affects the diffraction peaks of BEA where the diffraction peaks are shifted to slightly higher $2 \theta$ value and the intensity is reduced. This may be due to the formation of interacted species between $\mathrm{Fe}$ and $\mathrm{Ni}$ with $\mathrm{Al}_{2} \mathrm{O}_{3}$ or $\mathrm{SiO}_{2}$ in BEA. However, nickel aluminate $\left(\mathrm{NiAl}_{2} \mathrm{O}_{4}\right)$ and iron aluminate $\left(\mathrm{FeAl}_{2} \mathrm{O}_{4}\right)$ phase were not present, which could be due to lack of crystallinity as formerly observed by by Salagre et al. [16].

The variation in the TPR profile of $\mathrm{FeNi} / \mathrm{BEA}$ and $\mathrm{NiFe/BEA} \mathrm{catalysts} \mathrm{(Fig.} \mathrm{2)} \mathrm{shows} \mathrm{the} \mathrm{combination} \mathrm{of} \mathrm{nickel}$ and iron phases' reduction. The reduction of free $\mathrm{NiO}$ was observed at $400-500{ }^{\circ} \mathrm{C}$ [17]. On the other hand, the reductions of nickel and iron phase at $500-800{ }^{\circ} \mathrm{C}$ region were overlapped into a broad peak, which suggests the stabilization of $\mathrm{Fe}^{3+}$ and $\mathrm{Ni}^{2+}$ ions in the lattice. The reduction process transforms $\mathrm{Fe}_{2} \mathrm{O}_{3}, \mathrm{FeAl}_{2} \mathrm{O}_{4}$ and $\mathrm{NiAl}_{2} \mathrm{O}_{4}$ [17-18]. 

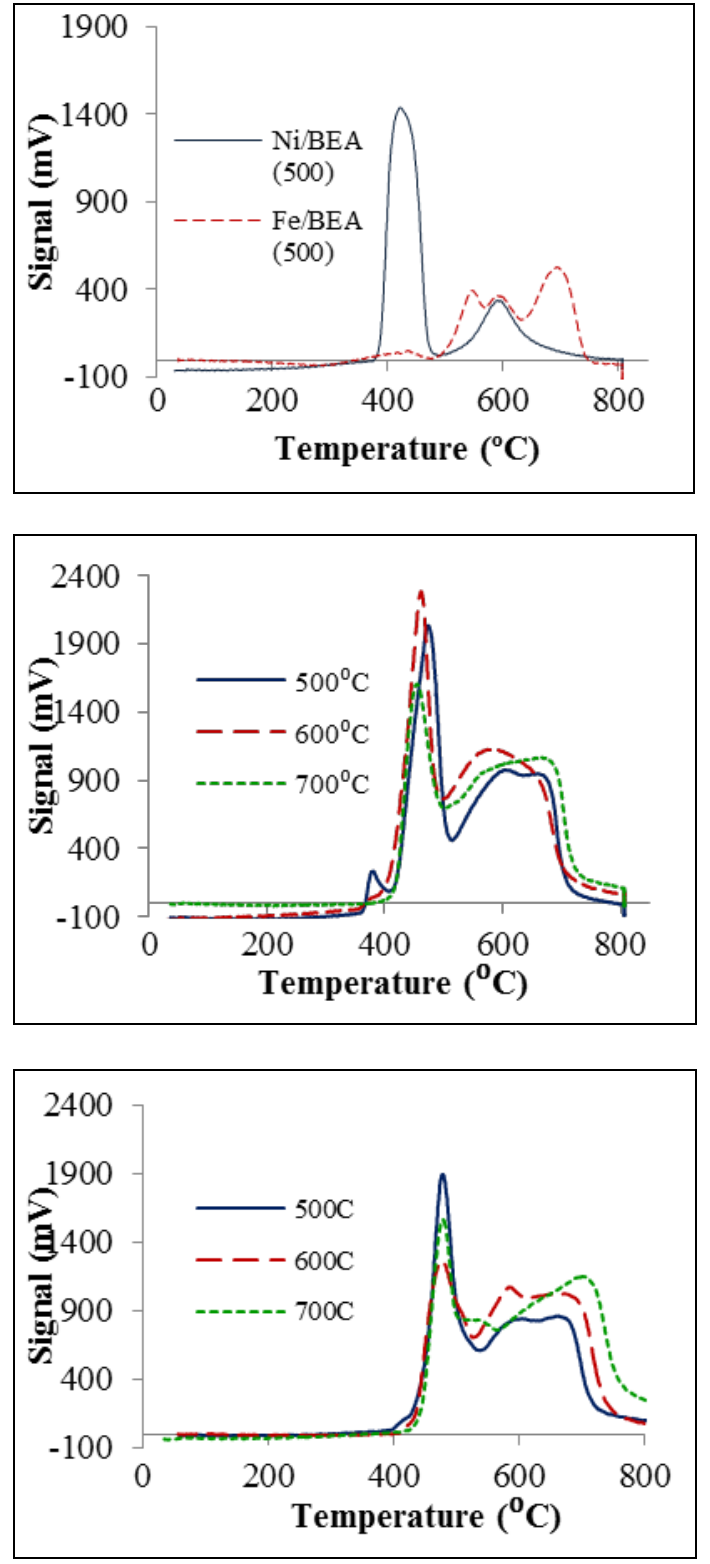

Fig. 2. TPR profile of (a) Ni/BEA and Fe/BEA as a reference (b) FeNi/BEA and (c) NiFe/BEA at different calcination temperatures

The presence of free $\mathrm{Fe}_{2} \mathrm{O}_{3}$ is noticeable with a small peak at $380{ }^{\circ} \mathrm{C}$ from TPR profile of FeNi/BEA (500). However, due to strong interaction of $\mathrm{Fe}$ and $\mathrm{Ni}$ at high temperature, the reduction peak of free $\mathrm{Fe}_{2} \mathrm{O}_{3}$ is significantly intensified and disappeared. This type of oxide is easily reduced and its existence can cause several difficulties during reaction such as sintering and carbon deposition on the catalyst surface which will lead to catalyst deactivation [19]. Apart from that, the reduction peak associated to the reduction of free $\mathrm{NiO}$ to $\mathrm{Ni}^{\circ}$ shifted towards lower temperature as the calcination temperatures increases. While, the reduction peak represents the reduction of several phases were shifted to higher temperature.

In the case of NiFe/BEA catalysts (Fig. 2c), the reduction peak representing reduction of several phases are divided into two peaks particularly after the catalyst was calcined at 700 ${ }^{\circ} \mathrm{C}$. For $\mathrm{NiFe} / \mathrm{BEA}$ (700), the peak represent the reduction of $\mathrm{Fe}^{3+}$ is shifted to lower temperature while the peak having strong interaction with support $\left(\mathrm{NiAl}_{2} \mathrm{O}_{4}\right.$ and $\left.\mathrm{FeAl}_{2} \mathrm{O}_{4}\right)$ is shifted to higher temperature. This indicates that addition of $\mathrm{Ni}$ as a second metal in this catalyst results in higher reducibility of $\mathrm{Fe}_{2} \mathrm{O}_{3}$ phase where it is reducible at lower temperature and active for the reaction. It is also observed that the reduction temperature of free $\mathrm{NiO}$ does not change even though the calcinations temperature of the catalyst was increased; however the intensity of the reduction peak is different.

\section{B. Catalytic Steam Gasification}

Fig. 3 shows the concentration of gases evolved from the steam gasification of PKS in the presence of BEA supported bimetallic catalysts. The results on monometallic Ni/BEA and Fe/BEA catalysts from previous work [12] are also reported for comparison. Addition of Fe to the Ni/BEA (500) to form FeNi/BEA (500) resulted in slight decrease in $\mathrm{H}_{2}$ and $\mathrm{CO}$ gas produced, which in turn increases the concentration of $\mathrm{CO}_{2}$ while there is no significant change in the $\mathrm{CH}_{4}$ evolved (Fig. 3a). This indicates that FeNi/BEA (500) is slightly less reactive in steam gasification, thus promoting combustion of PKS to $\mathrm{CO}_{2}$. This could be due to the presence of both fixed nickel oxide $\left(\mathrm{NiAl}_{2} \mathrm{O}_{4}\right)$ and fixed iron oxide $\left(\mathrm{FeAl}_{2} \mathrm{O}_{4}\right)$ as seen in Fig. 4b which suppresses the reduction of $\mathrm{Fe}_{2} \mathrm{O}_{3}$ and $\mathrm{NiO}$ with different state of interaction with BEA. Furthermore, presence of 'free iron oxide' at reduction temperatures between $380-400{ }^{\circ} \mathrm{C}$ in the catalyst could also be the reason in low catalytic activity of FeNi/BEA (500) catalyst since it promotes the formation of $\mathrm{CO}_{2}$ as well as loss of active phase during the reaction $[8,19]$

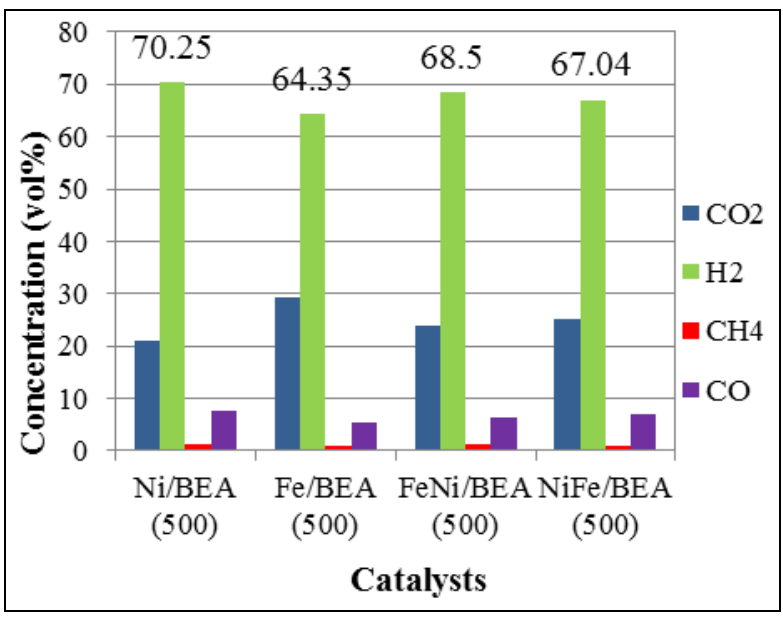



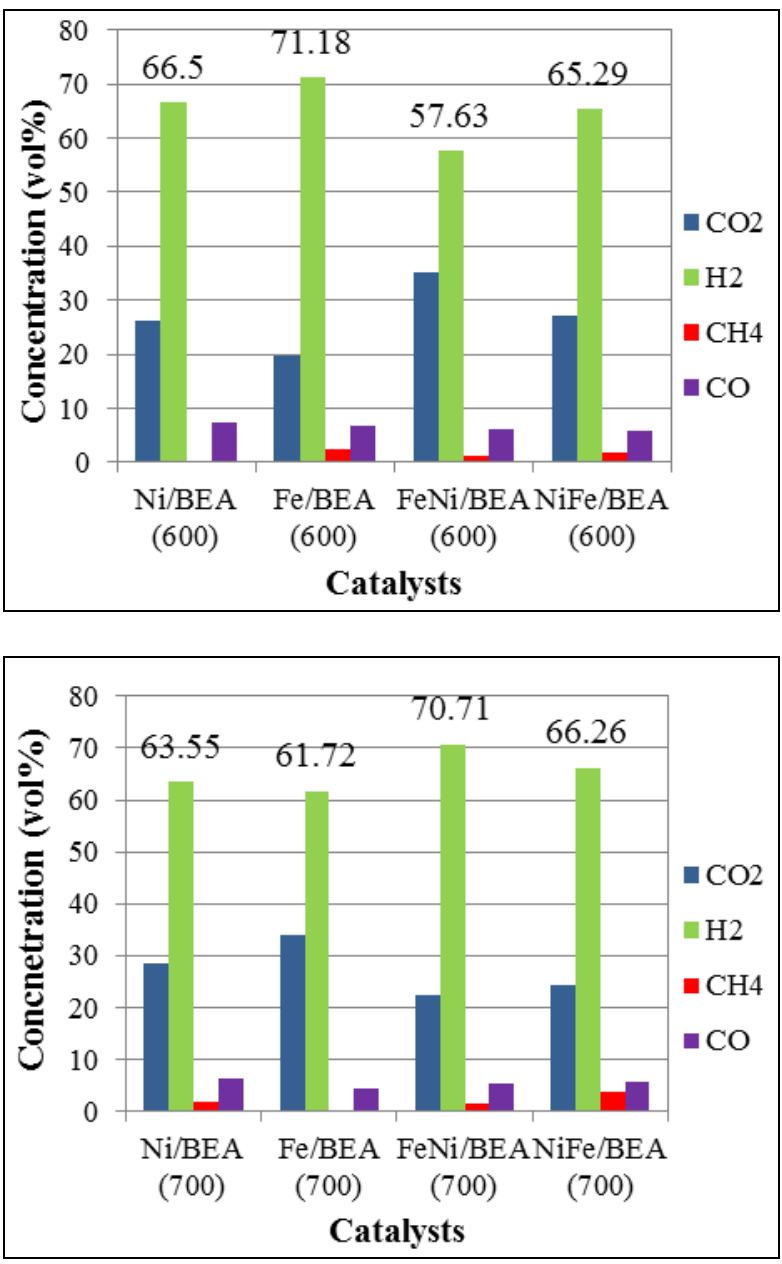

Fig. 3. Performance of the catalysts calcined at (a) $500{ }^{\circ} \mathrm{C}$ (b) $600{ }^{\circ} \mathrm{C}$ (c) 700 ${ }^{\circ} \mathrm{C}$ in steam gasification of PKS

Addition of Ni to Fe/BEA (500) to form NiFe/BEA (500) on the other hand, enhances the steam methane reforming whereby it leads to an improvement in the concentration of $\mathrm{H}_{2}$ produced and reduction of $\mathrm{CO}_{2}$ concentration in the product gas although there is slight increase in $\mathrm{CO}$ concentration. This could be due to reaction between $\mathrm{CH}_{4}$ and $\mathrm{H}_{2} \mathrm{O}$ in a $1: 1$ molar ratio on the catalyst active site to form a $1: 3$ molar ratio of $\mathrm{CO}$ and $\mathrm{H}_{2}$ during the steam methane reforming [2-3]. High performance of this catalyst may be attributed to bigger reduction peak at $500-700{ }^{\circ} \mathrm{C}$ in $\mathrm{H}_{2}$-TPR profile as compared to $\mathrm{Fe} / \mathrm{BEA}$ (500) whereby this peak is attributed to reduction of $\mathrm{Fe}_{2} \mathrm{O}_{3}$. Bigger reduction peak means more $\mathrm{H}_{2}$ consumption which means more $\mathrm{Fe}_{2} \mathrm{O}_{3}$ available within the catalyst system thus, the catalyst becomes more active for steam gasification due to availability of more active sites for the reaction to take place [20].
Addition of Fe to Ni/BEA (600) to form FeNi/BEA (600) follows the same trend as the catalyst calcined at $500{ }^{\circ} \mathrm{C}$ whereby it becomes no longer effective to promote steam gasification of PKS to produce $\mathrm{H}_{2}$. Instead, the FeNi/BEA (600) promotes oxidation of $\mathrm{CO}$ or combustion of PKS which is shown by an increase in $\mathrm{CO}_{2}$ concentration. FeNi/BEA (600) also promotes the formation of $\mathrm{CH}_{4}$, presumable via reduction of $\mathrm{CO}$ as $\mathrm{CH}_{4}$ concentration slightly increases while CO concentration slightly decreases. This may be due to insufficient presence of steam content during the reaction and presence of metallic Fe from over reduction of $\mathrm{Fe}_{2} \mathrm{O}_{3}$ which resulted in reduction of $\mathrm{CO}$ with $\mathrm{H}_{2}$ to produce $\mathrm{CH}_{4}$ [21] Indeed, Chaiprasert and Vitidsant [22] have studied the effect of steam during the gasification of biomass and found that increasing of steam feed resulted in higher $\mathrm{H}_{2}$ evolved, lower $\mathrm{CO}_{2}$ formation and slightly decrease in $\mathrm{CH}_{4}$ because of watergas shift reaction and methane reforming.

Furthermore, addition of $\mathrm{Ni}$ to $\mathrm{Fe} / \mathrm{BEA}(600)$ to from $\mathrm{NiFe} / \mathrm{BEA}(600)$ resulted in reduction of $\mathrm{H}_{2}, \mathrm{CO}$, and $\mathrm{CH}_{4}$, evolved. This trend is similar as FeNi/BEA (600) whereby the concentration of $\mathrm{CO}_{2}$ increases indicating that $\mathrm{NiFe} / \mathrm{BEA}$ (600) is less reactive in steam gasification, thus promoting $\mathrm{PKS}$ to undergo oxidation of $\mathrm{CO}$ to produce more $\mathrm{CO}_{2}$.

Addition of Fe to Ni/BEA (700) to form FeNi/BEA (700) in contrast, exhibited higher concentration of $\mathrm{H}_{2}$. A slight decrease in CO concentration indicates that FeNi/BEA (700) promotes the water gas shift reaction even though slight decrease in concentration of $\mathrm{CO}_{2}$ was observed. However, there is no significant difference in the concentration of $\mathrm{CH}_{4}$ evolved. As stated in the $\mathrm{H}_{2}$-TPR analysis, the addition of $\mathrm{Fe}$ as the second metal and calcined at $700{ }^{\circ} \mathrm{C}$ significantly improves the reducibility of $\mathrm{NiO}$ phase by reducing at low temperature. As a result, more active metals react with PKS to produce $\mathrm{H}_{2}$ gas and facilitate the water gas shift reaction. Therefore, this indicates that FeNi/BEA (700) is active in steam gasification reaction; hence it is able to prevent the PKS from undergoing oxidation. The results are consistent with the work reported by Chaipraset and Vitidsant [9] whereby the presence of $\mathrm{Fe}$ as the second metal in $\mathrm{Ni}$ based catalyst enhances the water-gas shift reaction and amplified the $\mathrm{H}_{2}$ production.

Addition of Ni to Fe/BEA (700) to form NiFe/BEA (700) also results in an increase in concentration of $\mathrm{H}_{2}$ and reduction of $\mathrm{CO}_{2}$ in the product gas. A slight increase in $\mathrm{CO}$ concentration indicates that NiFe/BEA (700) follows the same trend as the $\mathrm{NiFe} / \mathrm{BEA}(500)$ catalyst whereby it facilitates the reduction of $\mathrm{Fe}^{3+}$ and enhances the steam methane reforming. However, high concentration of $\mathrm{CH}_{4}$ was observed may be due to NiFe/BEA (700) also promotes the formation of $\mathrm{CH}_{4}$ through methanation. This possibly attributed to majority of $\mathrm{Ni}$ metals on the surface of the catalyst whereby $\mathrm{Ni}$ is the first component to be reduced at $450{ }^{\circ} \mathrm{C}$ as reported in $\mathrm{H}_{2}$-TPR. Hence, this favours the methane steam reforming and methanation reaction on $\mathrm{Ni}$ surface [8] as opposed to water gas shift reaction on Fe surfaces [9].

The variations in the trends indicate that the concentration of $\mathrm{H}_{2}$ gas for $\mathrm{FeNi} / \mathrm{BEA}$ decreases in the order of calcination temperatures: FeNi/BEA (700) > FeNi/BEA (500) > 
FeNi/BEA (600). This is because doping of Fe into Ni/BEA at different calcination temperatures resulted in slightly higher surface area for FeNi/BEA (700) followed by FeNi/BEA (500) and FeNi/BEA (600) as observed in $\mathrm{N}_{2}$ adsorption-desorption. According to Chaipraset and Vitidsant [9], the catalyst with high surface area can provide large contact area for reactants and consequently enhance the reaction activity. However, $\mathrm{FeNi} / \mathrm{BEA}$ (700) has less reducibility as compared to FeNi/BEA (500) and FeNi/BEA (600).

The order of the $\mathrm{H}_{2}$ formation for NiFe/BEA catalysts is $\mathrm{NiFe} / \mathrm{BEA}$ (500) > NiFe/BEA (700) > NiFe/BEA (600), whereby the catalytic activity decreases with increasing in calcination temperatures. This behaviour is expected since NiFe/BEA (500) shows higher reducibility as compared to $\mathrm{NiFe/BEA} \mathrm{(600)} \mathrm{and} \mathrm{NiFe/BEA} \mathrm{(700).} \mathrm{This} \mathrm{can} \mathrm{be} \mathrm{explained}$ by integration of $\mathrm{Ni}$ and $\mathrm{Fe}$ in the BEA structure as observed in TPR analysis. The strong interaction of $\mathrm{Ni}$ and $\mathrm{Fe}$ at higher calcination temperatures (700) causes the stabilization of $\mathrm{Fe}^{3+}$ and $\mathrm{Ni}^{2+}$ ions in the lattice resulting in less reduction of metals. It is notable that the BET surface area of NiFe/BEA catalysts is in order NiFe/BEA (600) > NiFe/BEA (500) > $\mathrm{NiFe} / \mathrm{BEA}$ (700). Even though calcination at $600{ }^{\circ} \mathrm{C}$ leads to a bigger surface area, NiFe/BEA (500) still shows a higher catalytic activity due to its reducibility at lower temperature.

\section{CONCLUSION}

It can be inferred that different sequence of $\mathrm{Fe}$ and $\mathrm{Ni}$ as a second metal in bimetallic catalysts resulted in deviation in the catalyst properties and interaction between the active metals with support as well as the catalytic activity. Furthermore, both $\mathrm{Fe}$ and $\mathrm{Ni}$ are active for the steam gasification of PKS when they act as a second metal if the precursors were calcined at a suitable calcination temperature. The highest concentration of $\mathrm{H}_{2}$ evolvement in the steam gasification of PKS achieved in the presence of FeNi/BEA (700) and $\mathrm{NiFe} / \mathrm{BEA}$ (500). Incorporation of $\mathrm{Fe}$ as the second metal in the bimetallic catalyst and calcined at $700{ }^{\circ} \mathrm{C}$ improves the reducibility of $\mathrm{NiO}$ phase and enhances the water-gas shift reaction. While addition of $\mathrm{Ni}$ as the second metal facilitates the reduction of $\mathrm{Fe}_{2} \mathrm{O}_{3}$ phase and exhibits steam methane reforming. Hence, the second metal plays an important role and may act as a promoter to amplify the steam gasification reaction.

\section{ACKNOWLEDGMENT}

The authors are grateful for the financial support and facilities provided by UTP for this research and for granting a postgraduate scholarship to Siti Eda Eliana Misi.

\section{REFERENCES}

[1] Kimura, T., Miyazawa, T., Nishikawa, J., Kado, S., Okumura, K. Miyao, T., Naito, S., Kunimori, K., Tomishige, K. Development of Ni catalyst for tar removal by steam gasification of biomass. Appl. Catal. B. Vol. 68, pp.160-170, 2006.

[2] Mohammed, M. A. A., Salmiaton, A., Wan Azlina, W. A. K. G., Mohammad Amran, M. S., Fakhrul-Razi, A., Taufiq-Yap, Y. H. Hydrogen rich gas from oil palm biomass as a potential source of renewable energy in Malaysia. Renew. and Sustain. Ener. Rev. Vol. 15, pp. 1258-1270, 2011.

[3] McKendry, P. Energy production from biomass (Part 3): Gasification technologies. Bioresource Technol. Vol. 83, pp. 55-63, 2002.

[4] Sutton, D., Kelleher, B., Ross, J. R. H. Review of literature on catalyst for biomass gasification. Fuel Process. Technol. Vol. 73, pp. 155-173, 2001

[5] Asadullah, M., Miyazawa, T., Ito, S, Kunimori, K., Tomishige, K. Demonstration of real biomass gasification drastically promoted by effective catalyst. Appl. Catal. A. Vol. 246, pp. 103-116, 2003.

[6] Zhang, R., Wang, Y., Brown, R. C. Steam reforming of tar compounds over $\mathrm{Ni} /$ olivine catalysts doped with $\mathrm{CeO}_{2}$. Energy Conv \& Manage. Vol. 8, pp. 68-77, 2007.

[7] Uddin, M. A., Tsuda, H., Sasaoka, E. Catalytic decomposition of biomass tars with iron oxide catalyst. Fuel. Vol. 87, pp. 451-459, 2008.

[8] Swierczynksi, D., Libs, S., Courson, C., Kiennemann, A. Steam reforming of tar from biomass gasification process over $\mathrm{Ni}$ /olivine catalyst using toluene as a model compound. Appl. Catal. B. vol. 74, pp. 211-222, 2007.

[9] Chaiprasert, P., Vitidsant, T. Effect of promoters on biomass gasification using nickel/dolomite catalyst. Korean J. Chem. Eng. Vol. 26, pp. 15451549, 2009.

[10] Rapagna, S., Provendier, H., Petit, C., Kiennemann, A., Foscolo, P. U. Development of catalyst suitable for hydrogen or syn-gas production from biomass gasification. Biomass Bioenergy. Vol. 22, pp. 377-388, 2002.

[11] Swaan, H. M., Kroll, V. C. H., Martin, G. A., Mirodatos, C. Deactivation of supported nickel catalysts during the reforming of methane by carbon dioxide. Catal. Today. Vol. 21, pp. 571-578, 1994.

[12] Ramli, A., Misi, S. E. E., Mohamad, M. F., Yusup, S. $\mathrm{H}_{2}$ Production from Steam Gasification of Palm Kernel Shell in the Presence of 5\% Ni/BEA and 5\% Fe/BEA Catalysts, Advanced Science Letters, Vol. 19, pp. 950-954, 2013.

[13] Misi, S. E. E., Ramli, A. and Rahman, F. H. Characterization of structure feature of bimetallic Fe-Ni catalysts. J. Appl. Sci. Vol. 11(8), pp. 1297-1302, 2011.

[14] Kang, S. H., Bae, J. K. W. Fisher-Tropsch synthesis using zeolitesupported iron catalysts for the production of light hydrocarbons. Catal Lett. Vol. 125, pp. 264-270, 2008.

[15] Rynkowski, J. M., Paryjczak, T., Lenik, M. On the nature of oxidic nickel phase in $\mathrm{NiO} / \gamma-\mathrm{Al}_{2} \mathrm{O}_{3}$ catalysts. Appl. Catal. A. Vol. 106, pp. 7382, 1993.

[16] Salagre, P., Fierro, J. L. G., Medina, F., Sueiras, J. E. Characterization of nickel species on $\gamma$-alumina supported nickel samples. J. Mol. Catal. A. Vol. 106, pp. 125-134, 1996.

[17] Cheng, Z. X., Zhao, X. G., Li, J., Zhu, Q. M. Role of support in $\mathrm{CO}_{2}$ reforming of $\mathrm{CH}_{4}$ over Ni/ $\mathrm{Al}_{2} \mathrm{O}_{4}$ catalyst. Appl. Catal. A. Vol. 205, pp. 31-36, 2001.

[18] Wan, H. J., Wu, B. S., Zhang, C. H., Xiang, H. W., Li, Y. W., Xu, B. F., $\mathrm{Yi}, \mathrm{F}$. Study of $\mathrm{Fe}-\mathrm{Al}_{2} \mathrm{O}_{3}$ interaction over precipitated iron catalyst for fisher-tropsch synthesis. Catal. Commun. Vol. 8, pp. 1538-1545, 2007.

[19] Virginie, M., Libs, S., Courson, A., Kiennemann, A. (2008). Iron/olivine catalysts for tar reforming: comparison with nickel/olivine. [Online]. Available: http://gdricatal.univlille1.fr/GDRI\%20FR/21-28.pdf

[20] Wang, L., Li, B., Koike, M., Koso, S., Nakagawa, Y., Xu, Y. Catalytic performance and characterization of $\mathrm{Fe}-\mathrm{Ni}$ catalysts for the steam reforming of tar from biomass pyrolysis to synthesis gas. Appl. Catal. A. Vol. 392, pp. 248-255, 2011.

[21] Aznar, M. P., Caballero, M. A., Corella, J., Molina, G., Toledo, J. M. Hydrogen production by biomass gasification with steam- $\mathrm{O}_{2}$ mixtures followed by a catalytic steam reformer and a CO-shift system. Energy and Fuels. Vol. 20, pp. 1305-1309, 2006

[22] Chaiprasert, P., Vitidsant, T. Promotion of coconut shell gasification by steam reforming on nickel-dolomite. Am. J. Appl. Sci. Vol. 6(2), pp. 332-336, 2009.

\section{Creative Commons Attribution License 4.0 (Attribution 4.0 International, CC BY 4.0)}

This article is published under the terms of the Creative Commons Attribution License 4.0 https://creativecommons.org/licenses/by/4.0/deed.en_US 